\title{
Identification of Vibrio harveyi isolated from diseased cultured wedge sole Dicologoglossa cuneata
}

\author{
Jose R. López ${ }^{1, *}$, Elena de la Roca ${ }^{1}$, Soledad Núñez ${ }^{2}$, Roberto de la Herran ${ }^{3}$, \\ José I. Navas ${ }^{1}$, Manuel Manchado ${ }^{4}$, Marcelino Herrera ${ }^{1}$, Alicia E. Toranzo ${ }^{2}$ \\ ${ }^{1}$ IFAPA Centro Agua del Pino, Junta de Andalucía, 21450 Huelva, Spain \\ ${ }^{2}$ Departamento de Microbiología y Parasitología, Facultad de Biología e Instituto de Acuicultura, Universidad de Santiago, \\ 15782 Santiago de Compostela, Spain \\ ${ }^{3}$ Departamento de Genética, Facultad de Ciencias, Universidad de Granada, 18071 Granada, Spain \\ ${ }^{4}$ IFAPA Centro El Toruño, Junta de Andalucía, 11500 Cádiz, Spain
}

\begin{abstract}
We report the first isolation of Vibrio harveyi from wedge sole Dicologoglossa cuneata. The pathogen was recovered from ulcers and internal organs of ailing cultured fish, from 7 different outbreaks between 2004 and 2006. The 15 isolates found were phenotypically characterized using biochemical tests and BIOLOG GN plates, which revealed high phenotypic diversity. Diagnosis was confirmed with PCR using $V$. harveyi specific primers and partial 16S and 23S rRNA gene sequencing. A virulence evaluation of the isolates was also performed using fry and juvenile wedge sole. Significant mortalities were recorded by intraperitoneal injection; however, no mortalities were recorded by bath immersion.
\end{abstract}

KEY WORDS: Vibrio harveyi $\cdot$ Characterization $\cdot$ Wedge sole $\cdot$ Dicologoglossa cuneata $\cdot$ Virulence

\section{INTRODUCTION}

Vibrio harveyi, which now includes $V$. carchariae and $V$. trachuri as junior synonyms (Pedersen et al. 1998, Thompson et al. 2002), is a Gram-negative, luminous, marine bacterium that is ubiquitous in warm nearshore marine waters and sediment, the surfaces of marine animals, light-emitting organs of marine fish and cephalopods, and is considered to be a normal component of the intestinal microbiota of aquatic vertebrates and invertebrates (O'Brien \& Sizemore 1979, Orndorff \& Colwell 1980, Ramesh \& Venugopalan 1989, Pang et al. 2006). It is one of the most frequently isolated marine Vibrio species (Arias et al. 1999, Pujalte et al. 1999, 2003) and has been considered the main causative agent of luminous vibriosis, which affects a diverse range of marine invertebrates, especially cultured larval and juvenile penaeid shrimp, resulting in severe economic losses (Liu et al. 1996, Robertson et al. 1998, Diggles et al. 2000). This bac- terium has been also reported as a serious pathogen causing significant mortalities in various fish species over a wide geographical area (Saeed 1995, Hispano et al. 1997, Company et al. 1999, Zhang \& Austin 2000, Liu et al. 2003, 2004, Arijo et al. 2005). Nevertheless, although some strains are highly pathogenic to aquatic fauna, other strains may be considered opportunistic pathogens (Oakey et al. 2003). In fish, the main symptoms of infection include skin ulcers, eye lesions, vasculitis and gastro-enteritis (Austin \& Zhang 2006). In flatfishes, $V$. harveyi has been associated with outbreaks affecting farmed Senegalese sole Solea senegalensis causing moderate mortalities, with the occurrence of skin ulcers as well as haemorrhagic areas near the fins and mouth as the main external signs of the disease (Zorrilla et al. 2003, Rico et al. 2008).

Taxonomically, Vibrio harveyi is closely related to $V$. parahaemolyticus, V. alginolyticus, V. campbellii and V. rotiferianus (Conejero \& Hedreyda 2003, Oakey et al. 2003, Thompson et al. 2007). Identification of $V$. har- 
veyi is often problematic because of both phenotypic and genotypic diversity (Austin \& Austin 1989, Oakey et al. 2003). In particular, $V$. harveyi displays a high phenotypic heterogeneity and has been extremely difficult to identify using only conventional bacteriological tests (Vandenberghe et al. 2003). Several speciesspecific PCR methods have been developed to identify $V$. harveyi isolates, although in some cases false-positive (e.g. Oakey et al. 2003) or false-negative results (Conejero \& Hedreyda 2003) have been recorded. Other molecular tools, such as amplified fragment length polymorphism (AFLP), multilocus sequence analysis (MLSA), DNA-DNA hybridization and 16S rDNA gene sequencing have also been used for identification of this species (Gomez-Gil et al. 2004, Thompson et al. 2004, 2007).

The present paper reports the first description of Vibrio harveyi as responsible for vibriosis in cultured wedge sole Dicologoglossa cuneata, an economically valuable flatfish species belonging to the Family Soleidae, which is being cultured in some farms in southwestern Spain in an effort to diversify marine aquaculture. The production of this species is affected by pathological problems that cause severe losses, necessitating the identification of the pathogens and the development of prevention and treatment techniques to optimise farming conditions (Herrera et al. 2008). Studies carried out to confirm the identification of the isolates as $V$. harveyi as well as its involvement in the disease are reported here.

\section{MATERIALS AND METHODS}

Bacterial isolation. Sampled fish came from 7 epizootic outbreaks that occurred between August 2004 and April 2006 in wedge sole cultured in 2 marine farms located in southwestern Spain (Table 1). Mortalities occurred in fry, juvenile and adult stages of wedge sole ( 0.6 to $150 \mathrm{~g}$ ) stocked at 0.8 to $3 \mathrm{~kg} \mathrm{~m}^{-2}$. Water temperature varied from 10 to $22^{\circ} \mathrm{C}$ and water salinity was $32 \pm 4 \%$. Samples for bacterial isolation were taken from ulcers, liver and kidney of moribund wedge sole and cultured on Flexibacter maritimus medium (FMM) (Pazos et al. 1996) at $20^{\circ} \mathrm{C}$ for 24 to $96 \mathrm{~h}$. Isolates were subcultured onto tryptic soy agar (TSA) supplemented with sterile seawater (TSA-SW).

Phenotypic characterization of the isolates. Pure cultured colonies were characterized using phenotypic tests basically as reported by MacFaddin (1980) and Smibert \& Krieg (1981). The following tests were performed: Gram (determined according to the potassium hydroxide $[\mathrm{KOH}]$ method proposed by Buck 1982); cell morphology; cytochrome oxidase (oxidase reagent, bioMérieux); catalase; motility; oxidative-fermentative test; growth on thiosulfate-citrate-bile salt-sucrose agar (TCBS); swarming on TSA-SW; growth in $0,3,6$, 8,10 and $12 \% \mathrm{NaCl}_{i}$ growth at $4,25,35$ and $40^{\circ} \mathrm{C}_{i}$ gas production from glucose; arginine dihydrolase; decarboxylation of lysine and ornithine; reduction of nitrate, Voges-Proskauer, Simmons citrate, indole and methyl red; acid production from arabinose, cellobiose,

Table 1. Bacterial strains used in this study

\begin{tabular}{|c|c|c|c|c|c|c|}
\hline Bacterial isolate & Source & Fish life stage & Isolated from & Farm & Origin & Date of isolation \\
\hline a9 & Wedge sole Dicologoglossa cuneata & Fry & Tail ulcer & $\mathrm{A}$ & Spain & August 2004 \\
\hline a20 & Wedge sole & Juvenile & Liver & A & Spain & September 2004 \\
\hline $\mathrm{a} 26$ & Wedge sole & Adult & Tail ulcer & $\mathrm{A}$ & Spain & January 2006 \\
\hline a30 & Wedge sole & Adult & Tail ulcer & $\mathrm{A}$ & Spain & January 2006 \\
\hline a82 & Wedge sole & Juvenile & Liver & $\mathrm{A}$ & Spain & October 2004 \\
\hline a87 & Wedge sole & Fry & Liver & $\mathrm{A}$ & Spain & October 2004 \\
\hline a91 & Wedge sole & Juvenile & Liver & A & Spain & November 2004 \\
\hline a102 & Wedge sole & Juvenile & Ulcer & A & Spain & December 2004 \\
\hline a106 & Wedge sole & Juvenile & Tail ulcer & A & Spain & December 2004 \\
\hline $\mathrm{a} 417$ & Wedge sole & Juvenile & Tail ulcer & $\mathrm{B}$ & Spain & April 2006 \\
\hline a421 & Wedge sole & Juvenile & Tail ulcer & $\mathrm{B}$ & Spain & April 2006 \\
\hline a426 & Wedge sole & Juvenile & Ulcer & $\mathrm{B}$ & Spain & April 2006 \\
\hline a428 & Wedge sole & Juvenile & Liver & $\mathrm{B}$ & Spain & April 2006 \\
\hline a456 & Wedge sole & Juvenile & Tail ulcer & $\mathrm{B}$ & Spain & April 2006 \\
\hline a459 & Wedge sole & Juvenile & Tail ulcer & B & Spain & April 2006 \\
\hline \multicolumn{7}{|l|}{ Reference strains } \\
\hline Vibrio harveyi & CECT 525 (luminescent amphipod) & & & & USA & 1965 \\
\hline V. harveyi & CECT 5156 (sea bass) & & & & & 1998 \\
\hline$V$. alginolyticus & CECT 521 (horse mackerel) & & & & Japan & 1972 \\
\hline$V$. alginolyticus & CECT 436 (food) & & & & & 1962 \\
\hline V. campbellii & CECT 523 (seawater) & & & & Hawaii & 1971 \\
\hline $\begin{array}{l}\text { V. parahaemo- } \\
\text { lyticus }\end{array}$ & CECT 511 (human patient) & & & & Japan & 1951 \\
\hline
\end{tabular}


sucrose, lactose, sorbitol, mannitol, mannose and salicine; and the extracellular enzymatic activities, namely urease, caseinase, gelatinase, lipase, amylase and hydrolysis of aesculin. Haemolytic activity was assayed on Columbia agar with $5 \%$ sheep blood (BD BBL). All tests were incubated aerobically at $20^{\circ} \mathrm{C}$. Strains were also streaked on luminescent agar $(25 \mathrm{~g}$ $\mathrm{l}^{-1}$ nutrient broth, $17.5 \mathrm{~g} \mathrm{l}^{-1} \mathrm{NaCl}, 4 \mathrm{~g} \mathrm{l}^{-1} \mathrm{MgCl}_{2}, 1 \mathrm{~g} \mathrm{l}^{-1}$ $\mathrm{KCl}, 15 \mathrm{~g} \mathrm{l}^{-1}$ agar, $1 \mathrm{l}$ distilled water) and observed after 18 and $24 \mathrm{~h}$ incubation at $20^{\circ} \mathrm{C}$.

Commercial miniaturized API 20E galleries (bioMérieux) were also used according to the manufacturer's instructions, with sterile seawater as the diluent and $20^{\circ} \mathrm{C}$ the incubation temperature. Drug sensitivity of the isolates was determined on Mueller-Hinton agar by the disc-diffusion method using the following chemotherapeutic agents (Oxoid): ampicillin (10 $\mathrm{\mu g}$ $\left.\operatorname{disc}^{-1}\right)$, novobiocin $\left(30 \mu \mathrm{g} \operatorname{disc}^{-1}\right)$ and the vibriostatic agent $\mathrm{O} 129$ (10 and $150 \mu \mathrm{g} \mathrm{disc}^{-1}$ ). Antibiogram readings were performed after $48 \mathrm{~h}$ incubation at $20^{\circ} \mathrm{C}$. For long-term preservation the bacterial isolates were frozen at $-80^{\circ} \mathrm{C}$ in sterile seawater supplemented with $15 \%$ glycerol.

Biolog GN analysis. Carbon-utilization tests were performed using GN2 MicroPlates (Biolog) as described in the manufacturer's manual. Pure cultures were harvested from Biolog Universal Growth media supplemented with $5 \%$ sheep blood and suspended in gram-negative/gram-positive (GN/GP) inoculating fluid (Biolog) adjusted to $52 \%$ turbidity. The suspension was then distributed into GN2 MicroPlates, each with 95 different carbon sources and tetrazolium dye as an indicator of metabolic activity. The plates were incubated for $24 \mathrm{~h}$ at $30^{\circ} \mathrm{C}$ and read with the MicroLog 3 MicroStation System (Biolog). The results were interpreted with the MicroLog 3 v. 4.20 .05 database and software. A number of reference strains (Vibrio harveyi strains CECT 525 and CECT 5156, V. parahaemolyticus CECT 511 and $V$. alginolyticus strains CECT 521 and CECT 436) were included as controls to determine the specificity of the identification system.

Identification by PCR. Bacterial strains were identified as Vibrio harveyi by a PCR assay using the $V$. harveyi specific primers toxRF1 and toxRR1 (Pang et al. 2006). DNA was extracted from a single bacterial colony by boiling for $10 \mathrm{~min}$ in distilled water and quantified using a spectrophotometer. PCR assay was made in a $50 \mu$ l reaction mixture containing $200 \mathrm{nM}$ of each primer, $200 \mu \mathrm{M}$ of each dNTP, $1 \times$ PCR buffer containing $2 \mathrm{mM} \mathrm{MgCl}_{2}$ (Biotools), $1.25 \mathrm{U}$ of DNA polymerase (Biotools) and approximately 100 ng DNA template, following the PCR-cycling conditions described by Pang et al. (2006). PCR products were electrophoresed in a $1 \%$ agarose gel and stained with SYBR Safe DNA Gel Stain (Invitrogen). A 100 bp lad- der (Biotools) served as the molecular marker. V. harveyi strains CECT 525 and CECT 5156 were used as positive controls while $V$. parahaemolyticus CECT 511, V. alginolyticus strains CECT 521 and CECT 436 and V. campbellii CECT 523 were used as negative controls. The use of distilled water without DNA also served as a negative control.

16S and 23S rDNA sequencing and phylogenetic analysis. Partial 16S rRNA gene sequences of 5 Vibrio harveyi strains were obtained using universal primers 20F and 1500R, described by Weisburg et al. (1991), or those described by Labella et al. (2006). Primers 20F and 1500R are capable of amplifying nearly full-length 16S rDNA. The primers described by Labella et al. (2006) yield an amplicon of 833 bp. In addition, partial 23S rRNA gene sequences of about $400 \mathrm{bp}$ were obtained from $8 \mathrm{~V}$. harveyi strains using primers 16/23S-F and 16/23S-R, described by Lee et al. (2002). DNA extraction and PCR reactions were performed as previously indicated. Reaction cycles consisted of an initial denaturing at $94^{\circ} \mathrm{C}$ for $5 \mathrm{~min}, 35$ cycles at $94^{\circ} \mathrm{C}$ for $1 \mathrm{~min}$ each, $54^{\circ} \mathrm{C}$ for $45 \mathrm{~s}, 72^{\circ} \mathrm{C}$ for $45 \mathrm{~s}$, and a final extension of $72^{\circ} \mathrm{C}$ for $5 \mathrm{~min}$. PCR products were purified with the commercial kit GenElute PCR Clean-up (Sigma) following the manufacturer's instructions. The purified PCR products were directly sequenced using the kit BigDye Terminator v. 3.1 Cycle Sequencing (Applied Biosystems) and an ABI Prism 3130 DNA Sequencer (Applied Biosystems). The sequences were analysed using Chromas LITE v. 2.01 and Seqman II (DNASTAR) programs and subjected to basic local alignment search tool (BLAST) searches to retrieve the most closely related sequences.

The partial sequences of $16 \mathrm{~S}$ and $23 \mathrm{~S}$ rDNA were aligned with sequences of other Vibrio species and related organisms using Clustal X software and 2 phylogenetic trees were constructed according to the neighbour-joining method (Saitou \& Nei 1987) by using the program MEGA 3.1. The accuracy of the resulting trees was measured by bootstrap resampling of 1000 replicates.

Pathogenicity assays. To investigate the pathogenicity of the isolates, some preliminary experimental infection tests were performed by 2 routes of infection, intraperitoneal injection and immersion. Two groups of 10 healthy wedge soles, one group with an average fish weight of ca. $2 \mathrm{~g}$ and the other with an average fish weight of ca. $15 \mathrm{~g}$, were challenged by intraperitoneal injection of Vibrio harveyi at a concentration of $10^{6}$ cells per fish. In addition, groups of 10 fish having an average fish weight of ca. $4 \mathrm{~g}$ were challenged by immersion in a bath for $18 \mathrm{~h}$, as described by Avendaño-Herrera et al. (2006a), containing a V. harveyi suspension of $10^{7}$ cells $\mathrm{ml}^{-1}$. Assays were conducted in duplicate. The bacterial concentration was estimated 
by absorbance of bacterial cultures (grown in FMM broth at $20^{\circ} \mathrm{C}$ ) at $600 \mathrm{~nm}$ wavelength, recorded with a NanoDrop 1000 spectrophotometer. Doses were confirmed with total viable counts after spreading $0.1 \mathrm{ml}$ volumes of each dose over the surface of duplicate plates of FMM. After the harvesting, microorganisms were washed and resuspended in PBS. A control group of 10 fish (challenged with PBS only) was included in each virulence assay. After the bacterial challenge, experimental and control fish were kept in 181 tanks at $20^{\circ} \mathrm{C}$ in continually flowing seawater, and mortalities were recorded daily for an $18 \mathrm{~d}$ period. Dead fish were removed and subjected to standard bacteriological examination.

\section{RESULTS}

\section{Isolation and characterization of the bacterial strains}

Mortalities affected fry, juvenile and adult wedge sole. Fry and juvenile outbreaks alternated with periods of low but continuous mortalities. Mass mortality episodes reached rates of 5 to $30 \%$ mortality over a period of 1 to $3 \mathrm{wk}$. Cumulative mortality in some cases reached 80 to $90 \%$ in 3 to 6 mo. The only adult outbreak showed a lower mortality rate $(9 \%$ over a period of $2 \mathrm{mo}$ ). The main external signs detected were body ulcers and tail rot. Other affected fish showed no external symptoms. In general, there were no apparent internal signs of disease, but in some cases a haemorrhagic or pale liver was noted. Fifteen putative Vibrio harveyi strains (Table 1) were recovered from internal organs and external lesions, invariably in mixed cultures (frequently together with Tenacibaculum maritimum and/or T. soleae strains).

On the basis of morphological, physiological and biochemical characteristics, pure cultures of the isolates were tentatively identified as Vibrio harveyi. All the strains were Gram-negative, facultative anaerobic, motile rods, able to grow in TCBS and positive for cytochrome oxidase and catalase. They were also positive for lysine decarboxylase, methyl red and indol; however, arginine dihydrolase and Voges-Proskauer tests were negative. Gas was not produced from glucose. Hydrolysis of gelatine, aesculine, casein, Tween 80 and starch were positive. All isolates produced acid from amygdalin, mannose, mannitol, sorbitol and cellobiose, but not from inositol, rhamnose, melibiose, lactose and sallicin. Nitrate was reduced. All strains showed swarming on TSA-SW and $\alpha$-haemolysis on sheep blood agar. No isolate showed luminescence. Growth was observed at 25 to $40^{\circ} \mathrm{C}$, but not at 4 or $44^{\circ} \mathrm{C}$. All strains grew in 3 to $8 \% \mathrm{NaCl}$, but none grew in 0,10 or $12 \% \mathrm{NaCl}$. All isolates showed the same drug resistance pattern, and were resistant to vibriostatic agent O/129 and ampicillin, but sensitive to novobiocin. The following tests showed variable results: ornithine decarboxylase, citrate, urea, acid from arabinose and sucrose, and $\beta$-galactosidase. On the other hand, some discrepancies between classical biochemical tests and the API 20E kit were observed, the latter giving false negative results for tests such as ornithine decarboxylase, citrate, indol and urease.

\section{Biolog GN analysis}

Data obtained from GN MicroPlates (Biolog) for wedge sole isolates and Vibrio harveyi reference strains are summarized in Table 2. Most strains were positive for 14 carbon sources $(\alpha$-cyclodextrin, dextrin, glycogen, N-acetyl-D-glucosamine, D-cellobiose, Dfructose, $\alpha$-D-glucose, maltose, D-mannitol, D-mannose, D-trehalose, D-gluconic acid, D,L-lactic acid and inosine) and negative for 58 others. Variable results were found in the remaining 23 tests. Most isolates were identified by MicroLog 3 software as probable $V$. alginolyticus, followed by $V$. carchariae with a lower probability. Reference strains $V$. harveyi CECT 525, V. alginolitycus CECT 436 and CET 521 and V. parahaemolyticus CECT 511 were correctly identified by Biolog software. However, V. harveyi CECT 5156 recorded results similar to that of wedge sole isolates.

\section{Identification by PCR}

Identification of bacteria as Vibrio harveyi was confirmed by PCR using primers toxRF1 and toxRR1 described by Pang et al. (2006). All wedge sole strains showed the expected $382 \mathrm{bp}$ band, identical to the $V$. harveyi reference strains. No amplification product was detected in the other Vibrio species included in the analysis.

\section{$16 \mathrm{~S}$ and 23S rDNA sequencing and phylogenetic analysis}

Partial 16S rDNA sequences were obtained from strains a91, a9, a20, a87 and a106 (accession numbers FM162398-FM162400 and FM162402-FM162404) and used for BLAST homology searches. Strain a91 sequence (1409 bp) showed the following similarities: Vibrio harveyi strains LMG 4404T and NCIMB 1280T, $99 \%$; V. harveyi ATCC 14126T, V. carchariae ATCC 35084T, V. trachuri LMG 19643, V. parahaemolyticus RIMD 2210633, $V$. rotiferianus LMG 21460 and $V$. campbellii ATCC 25920T, $98 \%$; V. alginolyticus ATCC 
Table 2. Differences in carbon compound utilization between the Vibrio harveyi strains isolated from wedge sole, $V$. harveyi CECT 5156 and $V$. harveyi CECT 525, determined using the Biolog GN system. All the strains used the following carbon sources: dextrin, D-fructose, $\alpha$-D-glucose, D-mannose and D-trehalose. No strain used adonitol, L-arabinose, D-arabitol, i-erythritol, L-fucose, gentiobiose, m-inositol, $\alpha$-D-lactose, lactulose, D-melibiose, D-psicose, D-raffinose, L-rhamnose, turanose, xylitol, methyl piruvate, mono-methyl succinate, acetic acid, cis-aconitic acid, citric acid, formic acid, D-galactonic acid lactone, D-galacturonic acid, D-glucosaminic acid, $\alpha$-hydroxybutyric acid, $\beta$-hydroxybutyric acid, $\gamma$-hydroxybutyric acid, p-hydroxy phenylacetic acid, itaconic acid, $\alpha$-keto butyric acid, $\alpha$-keto glutaric acid, $\alpha$-keto valeric acid, malonic acid, propionic acid, quinic acid, D-saccharic acid, sebaric acid, succinamic acid, D-alanine, L-histidine, L-leucine, L-ornithine, L-phenylamine, L-pyroglutamic acid, D-serine, D,L-carnitine, $\gamma$-amino butyric acid, urocanic acid, thymidine, phenyethylamine, putrescine, 2-aminoethanol or 2,3-butanediol. Tests with variable results are shown in the table

\begin{tabular}{|c|c|}
\hline Substrate & Positive strains \\
\hline$\alpha$-cyclodextrin & All except CECT 525 and a20 \\
\hline Glycogen & All except a106 \\
\hline Tween 40 & a9, a91, a102 and a106 \\
\hline Tween 80 & CECT 525, a26 and a91 \\
\hline N-acetyl-D-galactosamine & CECT 5156, CECT 525, a87, a91, a417, a421, a426, a428 and a459 \\
\hline N-acetyl-D-glucosamine & All except a9 and a106 \\
\hline Cellobiose & All except a9 and a26 \\
\hline D-galactose & CECT 525, a20, a421 and a426 \\
\hline Maltose & All except a9 \\
\hline D-mannitol & All except a9 \\
\hline$\beta$-methyl-D-glucoside & CECT 525 \\
\hline D-sorbitol & CECT 5156 and a91 \\
\hline Sucrose & All except a26, a30, a82, a87 and a106 \\
\hline D-gluconic acid & All except a26 \\
\hline D-glucuronic acid & All except a9, a26, a91, a102 and a417 \\
\hline D,L-lactic acid & All except a9 \\
\hline Succinic acid & CECT 525, a30, a82, a87, a91, a102, a417, a428 and a459 \\
\hline Bromo succinic acid & All except CECT 5156, a26, a82, a87 and a106 \\
\hline Glucuronamide & CECT 525, a26 and a428 \\
\hline Alaninamide & All except a9, a26, a30, a82 and a106 \\
\hline L-alanine & СЕCT 5156, CECT 525, a9, a87, a91, a102, a417, a421, a426 and a428 \\
\hline L-alanyl-glycine & CECT 525, a20, a91, a417, a421, a426, a428 and a459 \\
\hline L-asparagine & CECT 525 \\
\hline L-aspartic acid & CECT 525, a87, a102, a106, a417, a426, a428 and a459 \\
\hline L-glutamic acid & All except CECT 5156, a9, a20, a26, a91 and a417 \\
\hline Glycyl-L-aspartic acid & CECT 525, a87, a91, a421, a426, a428 and a459 \\
\hline Glycyl-L-glutamic acid & CECT 525, a30, a87, a91, a428 and a459 \\
\hline Hydroxy L-proline & CECT 525 and a459 \\
\hline L-proline & CECT 525 and a459 \\
\hline L-serine & CECT 5156, a87 and a428 \\
\hline L-threonine & CECT 5156, CECT 525, a91, a102, a417, a421, a426, a428 and a459 \\
\hline Inosine & All except a26 \\
\hline Uridine & All except CECT 5156, a26, a30, a82, a87, a106, a417 and a421 \\
\hline Glycerol & $\mathrm{a} 20, \mathrm{a} 91, \mathrm{a} 102, \mathrm{a} 417, \mathrm{a} 421, \mathrm{a} 426, \mathrm{a} 428$ and $\mathrm{a} 459$ \\
\hline D,L- $\alpha$-glycerol phosphate & a9, a87, a91, a102, a417, a421, a426, a428 and a459 \\
\hline Glucose-1-phosphate & All except a9, a26, a106, a426 and a428 \\
\hline Glucose-6-phosphate & All except a9, a26 and a417 \\
\hline
\end{tabular}

$17749 \mathrm{~T}$ and $V$. natriegens ATCC 14048T, 97\%. A phylogenetic tree derived from these and other sequences was used to illustrate the position of this isolate (Fig. 1). Strain a91 was clearly grouped together with the other $V$. harveyi $16 \mathrm{~S}$ rDNA sequences. The other isolates $16 \mathrm{~S}$ rDNA sequences were identical to those of strain a91, although shorter (about 700 bp). They remained grouped together to $V$. harveyi reference strain sequences when a phylogenetic tree was constructed (data not shown), but showed inadequate discriminative power when BLAST searches were car- ried out (99\% similarity with $V$. harveyi, V. carchariae, V. campbellii, V. parahaemolyticus, V. alginolyticus, V. natriegens and $V$. fischeri).

On the other hand, partial 23S rDNA sequences were obtained from strains a20, a26, a30, a82, a91, a106, a417 and a421 (accession numbers FM956003FM956010). All these sequences showed the following similarities: Vibrio harveyi strain ATCC BAA-1116, 99\%; V. alginolyticus PD2, 93\%; V. alginolyticus ATCC 19108 and $V$. fischeri ES114, 92\%; V. mediterranei CECT 621T, $91 \%$; V. parahaemolyticus RIMD 


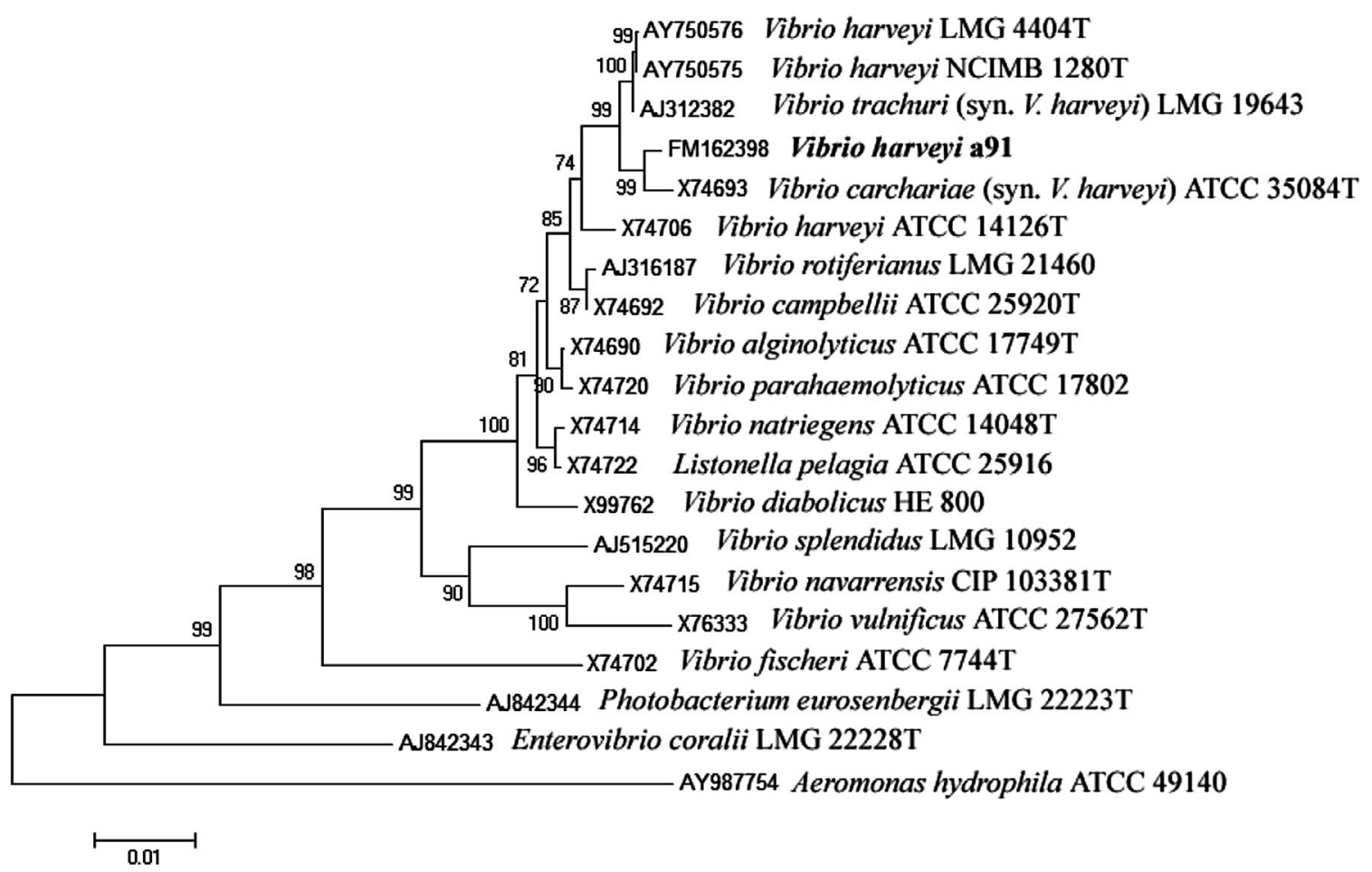

Fig. 1. Neighbour-joining phylogenetic tree based on 16S rDNA gene sequences showing the relationships between Vibrio harveyi a91, isolated from wedge sole (in bold text), and members of the genus Vibrio and other related genera. The Aeromonas hydrophila sequence was used as an outgroup. The numbers at the nodes indicate the levels of bootstrap based on 1000 replicates. Sequences from related species were obtained from GenBank database. Accession numbers are indicated before the species name

2210633, V. pelagius CECT 4202T and V. lentus CECT 5110T, 90\%; and V. splendidus CECT 4204, $89 \%$. Sequences from other related species as $V$. campbellii and $V$. rotiferianus were not available in the GenBank database and could not be tested. The phylogenetic tree derived from these sequences also clearly grouped wedge sole isolates together with the $V$. harveyi reference strain 23S rDNA sequence (Fig. 2).

\section{Pathogenicity tests}

The strain selected for experimental infections ( Vibrio harveyi a91) caused significant mortality to wedge sole by intraperitoneal injection, but not by bath immersion. By the intraperitoneal route $\left(10^{6}\right.$ cells fish $^{-1}$ ), mortality rates of 90 to $100 \%$ were observed 2 to $4 \mathrm{~d}$ post-exposure. Bath immersion $\left(10^{7}\right.$ cells $\left.\mathrm{ml}^{-1}\right)$ was ineffective in inducing wedge sole mortality and no casualties were registered within $18 \mathrm{~d}$. In addition, strains a82 and a417 were assayed once by the intraperitoneal route with $2 \mathrm{~g}$ fish, which displayed mortality rates of 80 and $40 \%$, respectively, 2 d after exposure. Experimentally infected fish did not reproduce the clinical signs of the disease, but the inocu- lated $V$. harveyi strain was recovered from all the dead fish. None of the control fish died during the different assays.

\section{DISCUSSION}

This work represents the first report of the marine pathogen Vibrio harveyi from farmed wedge sole. All isolates shared some unusual characteristics in V. harveyi descriptions, such as the ability to hydrolyze aesculin and to produce acid from sorbitol, and in some cases (33\% of tested strains) from arabinose. Despite this, its phenotypic characteristics agreed with those reported for $V$. harveyi, $V$. carchariae and $V$. trachuri from Alsina \& Blanch (1994), Buller (2004) and Noguerola \& Blanch (2008), and with those reported for $V$. harveyi strains isolated from Senegalese sole in southwestern Spain (also positive for aesculin and sorbitol tests in some described phenotypes) from Zorrilla et al. (2003) and Rico et al. (2008). Identification at the species level by using the Biolog system was inconclusive since most isolates were misidentified as $V$. alginolyticus. Nevertheless, they were correctly identified at the genus level and placed within the $V$. harveyi- 


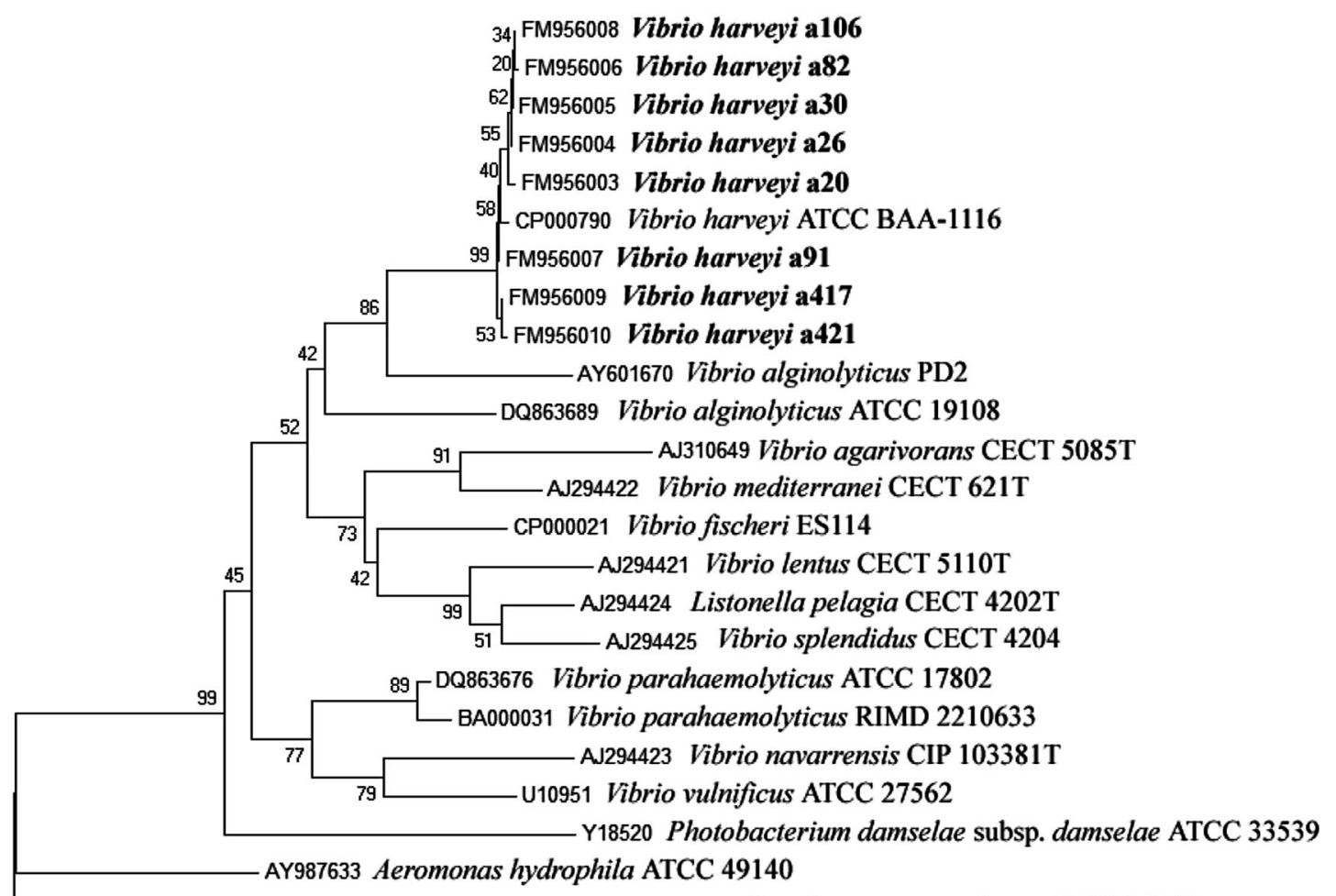

Y00432 Pseudomonas aeruginosa ATCC 10145

$\longmapsto 0.1$

Fig. 2. Neighbour-joining phylogenetic tree based on 23S rDNA gene sequences showing the relationships between Vibrio harveyi strains isolated from wedge sole (in bold text) and members of the genus Vibrio and other related genera. The Pseudomonas aeruginosa sequence was used as an outgroup. The numbers at the nodes indicate the levels of bootstrap based on 1000 replicates. Sequences from related species were obtained from GenBank database. Accession numbers are indicated before the species name

related species group. Because of $V$. harveyi phenotypic heterogeneity, identification was difficult using only conventional bacteriological tests, and thus a polyphasic approach was necessary. The $16 \mathrm{~S}$ and $23 \mathrm{~S}$ rDNA sequences of wedge sole isolates showed a high similarity with those from $V$. harveyi and were clearly differentiated to other Vibrio species when phylogenetic trees were constructed. The identification of isolates was confirmed by PCR using a pair of speciesspecific primers described by Pang et al. (2006). These primers are highly specific for the tox $R$ gene of $V$. harveyi and problems such as false-positive or false-negative results, experienced in other PCR protocols (Conejero \& Hedreyda 2003, Oakey et al. 2003), have not been reported. Lastly, virulence assays clearly demonstrate the pathogenic potential of wedge sole V. harveyi strains, although perhaps they should be considered as opportunistic pathogens. The lack of susceptibility of wedge sole to bath immersion may be associated with the absence of other determining factors, such as previous stressful situations, skin lesions or infections. In this sense, it is important to note that most strains were isolated together with Tenacibaculum maritimum or T. soleae strains, proven pathogens for flatfishes (Avendaño-Herrera et al. 2006b, PiñeiroVidal et al. 2008, López et al. in press).

Acknowledgements. This work was supported by INIA research project 2005-00215-C03 (Spanish Ministerio de Educación y Ciencia) together with the European Union FEDER program and a PhD grant from IFAPA (Junta de Andalucia, Spain).

\section{LITERATURE CITED}

Alsina M, Blanch A (1994) A set of keys for biochemical identification of environmental Vibrio species. J Appl Bacteriol 76:79-85

Arias CR, Macián MC, Aznar R, Garay E, Pujalte MJ (1999) Low incidence of Vibrio vulnificus among Vibrio isolates from seawater and shellfish of the western Mediterranean coast. J Appl Microbiol 86:125-134

Arijo S, Chabrillón M, Díaz-Rosales P, Rico R, Martinez-Manzanares $\mathrm{E}$, Balebona $\mathrm{MC}$, Toranzo AE, Moriñigo MA (2005) Bacteria isolated from outbreaks affecting cultured sole, Solea senegalensis (Kaup). Bull Eur Assoc Fish Pathol 25:148-154 
Austin B, Austin DA (1989) In: Methods for the microbiological examination of fish and shellfish. Ellis Horwood, Chichester

Austin B, Zhang XH (2006) Vibrio harveyi: a significant pathogen of marine vertebrates and invertebrates. Lett Appl Microbiol 43:119-124

> Avendaño-Herrera R, Toranzo AE, Magariños B (2006a) A challenge model for Tenacibaculum maritimum infection in turbot, Scophthalmus maximus (L.). J Fish Dis 29: $371-374$

Avendaño-Herrera R, Toranzo AE, Magariños B (2006b) Tenacibaculosis infection in marine fish caused by Tenacibaculum maritimum: a review. Dis Aquat Org 71: 255-266

Buck JD (1982) Nonstaining (KOH) method for determination of Gram reactions of marine bacteria. Appl Environ Microbiol 44:992-993

Buller NB (2004) Bacteria from fish and other aquatic animals: a practical identification manual. CABI Publishing, Wallingford

> Company R, Sitja-Bobadilla A, Pujalte MJ, Garay E, ÁlvarezPellitero P, Pérez-Sánchez J (1999) Bacterial and parasitic pathogens in cultured common dentex, Dentex dentex L. J Fish Dis 22:299-309

Conejero MJU, Hedreyda CT (2003) Isolation of partial toxR gene of Vibrio harveyi and design of toxR-targeted PCR primers for species detection. J Appl Microbiol 95: 602-611

> Diggles BK, Moss GA, Carson J, Anderson CD (2000) Luminous vibriosis in rock lobster Jasus verreauxi (Decapoda: Palinuridae) phyllosoma larvae associated with infection by Vibrio harveyi. Dis Aquat Org 43:127-137

Gomez-Gil B, Soto-Rodríguez S, García-Gasca A, Roque A, Vazquez-Juarez R, Thompson FL, Swings J (2004) Molecular identification of Vibrio harveyi-related isolates associated with diseased aquatic organisms. Microbiology 150:1769-1777

Herrera M, Hachero I, Rosano M, Ferrer JF, Marquez JM, Navas JI (2008) First results on spawning, larval rearing and growth of the wedge sole (Dicologoglossa cuneata) in captivity, a candidate species for aquaculture. Aquac Int 16:69-84

Hispano C, Nebra Y, Blanch AR (1997) Isolation of Vibrio harveyi from an ocular lesion in the short sunfish (Mola mola). Bull Eur Assoc Fish Pathol 17:104-107

- Labella A, Vida M, Alonso MC, Infante C and others (2006) First isolation of Photobacterium damselae ssp. damselae from cultured redbanded seabream, Pagrus auriga Valenciennes, in Spain. J Fish Dis 29:175-179

Lee SKY, Wang HZ, Law SHW, Wu RSS, Kong RYC (2002) Analysis of the 16S-23S rDNA intergenic spacers (IGSs) of marine vibrios for species-specific signature DNA sequences. Mar Pollut Bull 44:412-420

Liu PC, Lee KK, Chen SN (1996) Pathogenicity of different isolates of Vibrio harveyi in tiger prawn, Penaeus monodon. Lett Appl Microbiol 22:413-416

Liu PC, Lin JY, Chuang WH, Lee KK (2003) Infectious gastroenteritis caused by Vibrio harveyi (V. carchariae) in cultured red drum, Sciaenops ocellatus. J Appl Ichthyol 19:59-61

Liu PC, Lin JY, Chuang WH, Lee KK (2004) Isolation and characterization of pathogenic Vibrio harveyi ( $V$. carchariae) from the farmed marine cobia fish Rachycentron canadum L. with gastroenteritis syndrome. World J Microbiol Biotechnol 20:495-499

López JR, Nuñez S, Magariños B, Castro N, Navas JI, De la Herran R, Toranzo AE (in press) First isolation of Tenaci- baculum maritimum from wedge sole, Dicologoglossa cuneata (Moreau). J Fish Dis

MacFaddin JF (1980) Pruebas bioquímicas para la identificación de bacterias de importancia clínica. Editorial Médica Panamericana, Buenos Aires

> Noguerola I, Blanch AR (2008) Identification of Vibrio spp. with a set of dichotomous keys. J Appl Microbiol 105: 175-185

O'Brien CH, Sizemore RK (1979) Distribution of the luminous bacterium Beneckea harveyi in the semitropical estuarine environment. Appl Environ Microbiol 38:928-933

Oakey HJ, Levy N, Bourne DG, Cullen B, Thomas A (2003) The use of PCR to aid in the rapid identification of Vibrio harveyi isolates. J Appl Microbiol 95:1293-1303

Orndorff SA, Colwell RR (1980) Distribution and identification of luminous bacteria from the Sargasso Sea. Appl Environ Microbiol 39:983-987

Pang L, Zhang XH, Zhong Y, Chen J, Li Y, Austin B (2006) Identification of Vibrio harveyi using PCR amplification of the toxR gene. Lett Appl Microbiol 43:249-255

Pazos F, Santos Y, Macias AR, Nuñez S, Toranzo AE (1996) Evaluation of media for the successful culture of Flexibacter maritimus. J Fish Dis 19:193-197

Pedersen K, Verdonck L, Austin B, Austin DA and others (1998) Taxonomic evidence that Vibrio carchariae Grimes et al. 1985 is a junior synonym of Vibrio harveyi (Johnson and Shunk 1936) Baumann et al. 1981. Int J Syst Bacteriol 48:749-758

Piñeiro-Vidal M, Carballas CG, Gómez-Barreiro O, Riaza A, Santos Y (2008) Tenacibaculum soleae sp. nov., isolated from diseased sole (Solea senegalensis Kaup). Int J Syst Evol Microbiol 58:881-885

Pujalte MJ, Ortigosa M, Macián MC, Garay E (1999) Aerobic and facultative anaerobic heterotrophic bacteria associated with Mediterranean oysters and seawater. Int Microbiol 2:259-266

- Pujalte MJ, Sitja-Bobadilla A, Macián MC, Belloch C and others (2003) Virulence and molecular typing of Vibrio harveyi strains isolated from cultured dentex, gilthead sea bream and European sea bass. Syst Appl Microbiol 26: 284-292

Ramesh A, Venugopalan VK (1989) Response of enteric luminous bacteria to environmental conditions in the gut of the fish. J Appl Bacteriol 66:529-533

- Rico RM, Tapia-Paniagua S, Martinez-Manzanares E, Balebona MC, Moriñigo MA (2008) Characterization of Vibrio harveyi strains recovered from diseased farmed Senegalese sole (Solea senegalensis). J Appl Microbiol 105: 752-760

Robertson PAW, Calderón J, Carrera L, Stark JR, Zherdmant M, Austin B (1998) Experimental Vibrio harveyi infections in Penaeus vannamei larvae. Dis Aquat Org 32:151-155

Saeed MO (1995) Association of Vibrio harveyi with mortalities in cultured marine fish in Kuwait. Aquaculture 136: $21-29$

> Saitou N, Nei M (1987) The neighbor-joining method: a new method for reconstructing phylogenetic trees. Mol Biol Evol 4:406-425

Smibert RM, Krieg NR (1981) Systematics: general characterization. In: Gerhardt P, Murray RGE, Costilow RN, Nester EW, Wood NA, Krieg NR, Phillips GB (eds) Manual of methods for general bacteriology. American Society for Microbiology, Washington, DC, p 409-443

> Thompson FL, Hoste B, Vandemeulebroecke K, Engelbeen K, Denys R, Swings J (2002) Vibrio trachuri Iwamoto et al. 1995 is a junior synonym of Vibrio harveyi (Johnson and Shunk 1936) Baumann et al. 1981. Int J Syst Evol Micro- 
biol 52:973-976

Thompson FL, Iida T, Swings J (2004) Biodiversity of vibrios. Microbiol Mol Biol Rev 68:403-431

Thompson FL, Gomez-Gil B, Vasconcelos ATR, Sawabe T (2007) Multilocus sequence analysis reveals that Vibrio harveyi and V. campbellii are distinct species. Appl Environ Microbiol 73:4279-4285

Vandenberghe J, Thompson F, Gomez-Gil B, Swings J (2003) Phenotypic diversity amongst isolates from marine aquaculture systems. Aquaculture 219:9-20

Editorial responsibility: David Bruno,

Aberdeen, UK
Weisburg WG, Barns SM, Pelletier DA, Lane DJ (1991) 16S ribosomal DNA amplification for phylogenetic study. J Bacteriol 173:697-703

Zhang XH, Austin B (2000) Pathogenicity of Vibrio harveyi to salmonids. J Fish Dis 23:93-102

Zorrilla I, Arijo S, Chabrillón M, Díaz P, Martínez-Manzanares E, Balebona MC, Moriñigo MA (2003) Vibrio species isolated from diseased farmed sole, Solea senegalensis (Kaup), and evaluation of the potential virulence role of their extracellular products. J Fish Dis 26:103-108

Submitted: October 23, 2008; Accepted: February 11, 2009 Proofs received from author(s): April 2, 2009 